\title{
ABORDAJES TEÓRICO-CONCEPTUALES Y ELEMENTOS DE REFLEXIÓN SOBRE RURURBANIZACIÓN DESDE LOS ESTUDIOS TERRITORIALES
}

\section{DIANA MARCELA SÁNCHEZ-TORRES*}

Recibido: 15 de diciembre de 2017

Aprobado: 27 de julio de 2017

Artículo de Reflexión

* Doctoranda en Estudios Territoriales. Universidad de Caldas, Manizales, Colombia.

E-mail: dianamarcela.sancheztorres@gmail.com .DORCID: 0000-0002-3454-2890. Google Scholar 


\title{
Resumen
}

Objetivo. Aportar algunos elementos de reflexión y discusión sobre la rururbanización desde el campo de conocimiento de los estudios territoriales. Metodología. Se realizó una búsqueda de literatura relacionada con la temática. Resultados y conclusiones. Se plantean algunos interrogantes para contribuir al estudio de este fenómeno tales como ¿qué es la rururbanización?, ¿qué son las rururbanidades?, ¿quiénes han investigado sobre esta temática?, ¿a través de qué categorías se ha trabajado?, ¿a qué tipo de población hace alusión?, ¿qué retos y perspectivas podríamos plantear para continuar avanzando en su conocimiento?

Palabras clave: rururbanización, rururbanidades, territorio, paisaje, población urbana, campesinado.

\section{THEORETICAL-CONCEPTUAL APPROACHES AND ELEMENTS OF REFLECTION ON RUR-URBANIZATION FROM THE TERRITORIAL STUDIES}

\begin{abstract}
Objective. To contribute with some elements of reflection and discussion on the rur-urbanization from the field of knowledge of territorial studies. Methodology. A literature search related to the subject was conducted. Results and conclusions. Some questions are raised to contribute to the study of this phenomenon such as: What is rur-urbanization? What is rur-urbanities? Who has investigated on this subject? Through which categories has it been worked? To what type of population does it allude? What challenges and perspectives could we pose to continue learning about it?
\end{abstract}

Key words: rur-urbanization, rur-urbanities, territory, landscape, urban population, peasantry. 


\section{Introducción}

L as rururbanidades contemporáneas se han constituido a través de un proceso de transformación de los territorios rurales que ha significado un cambio en el espacio, tiempo, funciones del Estado y ejercicio del poder (Brown and Kulcsár, 2000; Deffontaines, 2003; Moquay, 2001; Pérez, 2001; Hierneaux, 2001; Gómez, 2001; Courlet, 2002; Nates y Raymond, 2007; Llambí, 2012; Elizalde y Thayer, 2013). Los cambios territoriales hoy implican una mirada crítica que involucra diferentes historias, geografías y sociabilidades que requieren de comprensiones teóricoepistemológicas y metodológicas integradoras, ya que frente a la geometría del poder los diferentes grupos sociales e individuos están situados de manera muy distinta en esos flujos e interconexiones (Massey, 1994).

La rururbanidad existe cuando hay una población asentada en franjas urbano-rurales, bien sea nativa por autoctonía o nativa por adopción (Nates, 2008); lo cual está asociado con la llegada de pobladores urbanos a territorios rurales que han sido constituidos por población con historias, arraigos e identidades forjadas en lo rural. Esto implica una constante producción de territorialidades urbano-rurales, desde modos de vida y relaciones socioecológicas, que convergen y generan matices en la construcción de nuevos territorios.

A su vez, la rururbanización es concebida como el proceso de encuentro entre lo urbano y lo rural en cuyo movimiento y territorialización se generan espaciotemporalmente rururbanidades. A partir de esta perspectiva, la vereda en Colombia es una de las unidades socioespaciales de análisis que permite objetivar claramente dichos cambios. Si bien la llegada de pobladores urbanos a un medio de tradición rural produce rururbanidades, también se afirma que estas se conforman a partir de pobladores campesinos que incorporan elementos de vida urbana (Sánchez, 2017). Por tal motivo este fenómeno permite reflexionar sobre el conjunto de relaciones que se manifiestan en el territorio a diferentes escalas, en la interacción de diversos espacios, desde elementos comunes y particulares en un contexto globalizado.

\section{Abordajes teórico-conceptuales sobre la rururbanización}

A continuación se presentan algunas tendencias en los estudios de rururbanización a partir de cuatro categorías de análisis: zonificación, paisaje, gentrificación y campesinado, lo que permite plantear una idea general sobre cómo se ha visto este fenómeno desde diversos autores. 
Metodológicamente este proceso se realizó a través de una consulta de fuentes secundarias, así como observaciones y reflexiones de la investigación de Sánchez (2017).

\section{Rururbanización y zonificación}

El fenómeno de la rururbanización ha sido ampliamente estudiado por aquellos que consideran que su influencia se teje en todo lo rural y por aquellos que establecen que solo una franja se ve influida con estas dinámicas. Los primeros que presentan esta tendencia son Pahl (1966), Clout (1976), Bauer y Roux (1976). El continuum rural-urbano planteado por Pahl (1966), trasciende las dicotomías polares de 'rural' y 'urbano'; ya que si se estableciera una dicotomía, esta sería en función de aspectos morfológicos del paisaje puesto que el continuum se refiere a aspectos culturales y sociales. Clout (1976) estudió el proceso de urbanización del campo y sus factores desencadenantes tales como el incremento de la riqueza, la eficiencia del transporte público y la gran cantidad de automóviles, estableciendo que lo rural ya no se define por lo agrario y que el desarrollo del turismo rural produce mayores beneficios económicos y sociales. En cuanto a la perspectiva de Bauer y Roux (1976), las áreas que rodean a las ciudades antiguas tienen una presencia dominante de viviendas unifamiliares, dispersas y aisladas, que cohabitan con la persistencia de áreas agrícolas y forestales. Esto deja entrever que la transformación de lo rural ha sido gradual y no excluye completamente lo antiguo (agricultura) que permanece con las nuevas construcciones.

Aportes más recientes (Macuacé y Cortés, 2013; Macuacé y Gómez, 2014) dan cuenta de los procesos de migración hacia los espacios rururbanos en Popayán, Colombia, para la primera década del siglo XXI. Se plantea que la ciudad se encuentra en continuo crecimiento, pero no lo hace de la misma manera en todas las direcciones; particularmente existen algunas zonas que se encuentran catalogadas como áreas de expansión que no presentan una dinámica de crecimiento como podría creerse y otras, en fronteras urbano-rurales, que experimentan gran crecimiento. Esta investigación arroja resultados diferentes a otros estudios sobre rururbanización, pues los autores establecen que el espacio rururbano se constituye a partir de la migración de la población rural hacia zonas de transición urbano-rural y no desde la migración de población urbana hacia entornos rurales.

A partir de la perspectiva de 'zonificación' como clasificación de franjas en el espacio, de acuerdo con García Ramón et al. (1995) se genera una especie de ordenamiento del territorio; aunque este sería un ordenamiento físico-espacial delimitado a: espacio urbano, periurbano, 
áreas urbanas con espacios discontinuos, semiurbano, semirural urbanizado, rural, rural-marginal. Esta investigación se encuentra en la misma línea teórica de Cardoso y Fritschy (2012), quienes postulan que el espacio rururbano debe ser claramente diferenciado del periurbano por cuanto el primero presenta un área de creciente expansión y superposición de elementos y funciones urbanas y rurales que forman una tensión y conflicto en la morfología del paisaje.

Sereno, Santamaría y Santarelli (2010) y Sereno y Santarelli (2012) plantean que lo rururbano se concibe como un espacio de contrastes, significados y pertenencias a través de la globalización de la economía, la reestructuración productiva y las innovaciones tecnológicas que provocan cambios en la gestión, producción y dinámica de los territorios que se constituyen en un espacio de vulnerabilidad y riesgo. Sin embargo esto interpela, pues la transformación de lo rururbano podría abarcar todo el espacio y no solo algunas franjas como si estuviésemos haciendo alusión a un espacio concebido que no dialoga con el espacio vivido al que hace alusión Lefebvre (2013). Por ello la zonificación podría ser funcional para planificar el territorio a corto plazo, desde aspectos físico-espaciales, pero no para asumir una transformación a largo plazo desde lo territorial.

Por su parte Bericat (2006) esboza el fenómeno de la rururbanización desde las desigualdades y la reestructuración funcional que esto conlleva. Sin embargo nos cuestionamos si todos los procesos de rururbanización generan desigualdades, ya que también se podrían establecer procesos de integración y coexistencia entre grupos sociales que anteriormente parecían divergentes sin dejar de lado las tensiones que puedan surgir. Mientras que Sánchez (2011, 2013) afirma que el concepto de interfase de Pesci (2007) puede emplearse en contextos urbano-rurales para los estudios ambientales y territoriales. Su estudio presenta el caso del corredor ambiental urbanorural entre las cuencas de los ríos Otún y Consotá de Pereira, Colombia, y la utilización de interfases como herramienta metodológica para analizar las interrelaciones socioecológicas entre espacios distintos que presentan convergencias.

Otros autores como Ávila (2009) hacen referencia al proceso de periurbanización, el cual comparte características con el de rururbanización en lo que se refiere a los efectos de la globalización en la expresión territorial de las megaciudades. Esto ha favorecido un proceso de dispersión urbana expresado en el desarrollo de nuevas y diversas actividades económicas donde históricamente se asentaron comunidades campesinas con cultura y procesos propios, así como el desarrollo de infraestructura urbana y de transporte en la expansión de las urbes. En esta línea Rivera Pabón (2013) ha estudiado en el Eje Cafetero, Colombia, los procesos de periubanización y 
rurubanización en las veredas Cambia del municipio de Risaralda (Caldas) y Condina en Pereira (Risaralda), postulando que la rururbanización es la llegada al espacio rural por gente del mundo urbano, identificando nuevas formas y tipologías urbanas asociadas a nuevas territorialidades en este proceso de rururbanización de élite. No obstante, la rururbanización no siempre corresponde a un proceso de élite con la llegada de población con mayor capacidad económica; ya que igualmente puede generarse la llegada de pobladores con baja capacidad adquisitiva, pero con raíces urbanas que se entrelazan a nuevas formas de vivir la ruralidad.

\section{Rururbanización y paisaje}

En México, España, Portugal, Perú, Chile y Argentina algunos estudios han relacionado 'rururbanización' y 'paisaje', por lo que consideramos pertinente citar algunos de estos abordajes. Para Errázuriz et al. (1998), en Chile, lo urbano y lo rural más que medios contrapuestos o antagónicos conforman los extremos de un continuum geográfico que al acercarse espacialmente configuran un paisaje donde se entremezclan elementos de ambos medios. Este paisaje intermedio se denomina rururbano y en el caso de estar rodeando una ciudad, recibe el nombre de franja o anillo rururbano. Esta noción ve al paisaje rururbano a través de las convergencias. Esto es bastante útil aunque no explica las "relaciones de poder" (Raffestin, 2011) e intereses económicos de los grupos sociales que constituyen el trasfondo de dicho paisaje.

En Perú, para Zucchetti y Chirinos (2001) el paisaje rururbano comprende complejos turísticos, industrias aisladas, complejos militares o centros de investigación en ámbitos esencialmente rurales. La visión que este estudio presenta de las organizaciones sociales campesinas se asemeja al discurso oficial de lo ilegal, lo 'pirata', que obstruye lo natural y las propiedades de los nuevos habitantes que se instalan en lo rural. Este discurso académico deslegitima los procesos sociales y culturales de las comunidades campesinas construidos a partir de su visión de mundo. Por su parte, en Argentina, para Lanson e Iglesias (2011), el paisaje rururbano se produce hasta donde influye el crecimiento metropolitano de la ciudad de Buenos Aires sobre un espacio que mantiene rasgos rurales con densidades de población y ritmos de crecimiento demográfico bajos. Por consiguiente, en los tres tramos de la cuenca del río Luján se entremezclan usos del suelo industriales, agrarios, residenciales y de servicio de diferente complejidad, aunque con el signo común de áreas de deterioro ambiental.

Según Alberto (2003), el paisaje rururbano corresponde a un espacio rural con modos de vidas no rurales. Es un escenario idílico con 
comodidades urbanas en un marco agropecuario; una creciente población no granjera en un contexto de complejos turísticos, industrias aisladas, centros de investigación, complejos militares en ámbitos rurales, así como grandes infraestructuras. Este trabajo es interesante dado que relaciona ambiente, paisaje y rururbanización; sin embargo no resulta muy claro el concepto de territorio y pareciera que lo ambiental se reduce a los recursos naturales, no siendo evidente lo social.

Para Soria y Goldwaser (2012), el paisaje rururbano corresponde al fortalecimiento de un nuevo mercado de turismo rural que está directamente ligado a la extensión de la autopista del Oeste y la reparación del camino que une la localidad de Carlos Keen con la ciudad de Lujan; el cual va generando revitalización de espacios históricos de finales del siglo XIX, el fomento de la gastronomía y la creación de artesanías que se convierten en el motor de la economía local. Lo anterior, desarrolla rasgos de homogeneidad a partir del turismo de fin de semana. Esta perspectiva cuestiona la globalización como proceso que refleja desigualdades, poniendo al descubierto los actores que tienen una posición ventajosa en el juego de poderes. Los nuevos emplazamientos turísticos, avanzan ocupando suelos agroganaderos para dar paso a otras actividades. Esto refleja unas adaptaciones, como el caso de las artesanías, pero también refleja unos cuestionamientos desde la continuidad de las actividades tradicionales y una lucha de poderes que se contraponen en el territorio.

De acuerdo con Crovetto (2011) el paisaje rururbano corresponde a una zona habitada, barrios aislados rodeados de una geografía visible, una urbanización parcial o discontinua donde el aislamiento o separación entre las aglomeraciones es discreta, perceptible y de clara identificación. El trabajo de Marcela Crovetto es bastante novedoso en cuanto a las categorías territoriales que emplea de territorios biográficos y territorios cotidianos, además de indicadores y un enfoque territorial flexible. $\mathrm{Su}$ abordaje del paisaje lo realiza desde todos los grupos poblacionales que habitan allí, sin enfocarse en algún grupo. De hecho, estos grupos no registran historia familiar campesina. Crovetto (2015) plantea que, en el contexto de los paisajes rururbanos, los territorios deben ser asumidos como enfoques y no solo como categorías de análisis; lo cual podría ser un camino productivo para la comprensión e interpretación de la vida social en diferentes contextos que aporten información más precisa para el diseño de políticas públicas, especialmente aquellas dirigidas al desarrollo rural. En este estudio emergen características similares a las de paisajes rururbanos del estudio de Sánchez (2017) por cuanto la migración de jóvenes rurales y su regreso al campo, dilucidan una incorporación y territorialización de elementos de vida urbana. 
Es novedoso el abordaje del paisaje rururbano desde el arte a través de los trabajos de Bran (2016), desde el caminar para cambiar de ambiente a partir de las emociones, desde la necesidad de tomar un respiro como lo establece la artista. Esto tiene mucho sentido porque es una visión que busca la complementariedad entre el espacio rural y el urbano, lo que no ocurre con aquellos pobladores urbanos que van a vivir en lo rural porque buscan permanentemente algo diferente. En este aspecto el trabajo de Martha Bran se relaciona con los estudios de Cosgrove (1998), al considerar las representaciones artísticas y particularmente pictóricas como artefactos culturales que dan cuenta de las relaciones de las sociedades con la tierra. A la vez Bastos (2014) afirma que el paisaje rururbano y las dinámicas asociadas a él, constituyen una buena excusa para tratar la cuestión de la representación de las identidades puesto que seguimos pensando binariamente en el espacio como 'rural' o 'urbano', apreciando la pureza de cada tipo y rechazando la mezcla paisajística por estar lejos del ideal de belleza o interés que recogen representaciones de las identidades de lo rural o lo urbano, al margen de la manera de vivir el espacio de las personas que lo construyen activamente. Desde su crítica a la película Os Verdes Anos cuestiona el papel de la modernización y del Estado que la favorece, reflejando las emociones de aquellos que se resisten al cambio y los que buscan adaptarse. El papel del arte para abordar temas territoriales es crucial en la reproducción de una visión crítica frente a las realidades sociales por cuanto influyen en el escenario político, impulsando diversas reacciones que pueden contribuir a generar mejores condiciones de participación e inclusión.

Por otra parte, el paisaje rururbano desde Lasanta y Errea (2012) se plantea a partir de los cambios de cultivos y ocupación de campos por urbanizaciones residenciales y fincas de recreo. Este estudio presenta un análisis sobre las posibles causas del cambio de la actividad hortícola por grandes extensiones de viñedos para responder a una demanda internacional de este producto. Esto es un reflejo de la influencia que tiene la globalización en la transformación de los territorios y, a su vez, el impacto de estos en la esfera global.

Sánchez (2013) establece que el paisaje rururbano puede entenderse como aquel espacio en el que se mezclan paisajes urbanos y rurales, yuxtaponiéndose y compitiendo por esas áreas. De esta forma se puede decir que el paisaje es consecuencia de la interacción entre esos componentes. Es valioso el aporte de esta autora desde las interacciones que surgen en el paisaje rururbano. Tanto los espacios rurales como urbanos se contraponen porque las demandas económicas y políticas así lo provocan, visibilizando en el paisaje lo que funcionalmente posibilita mayores ingresos económicos para las ciudades. 
Finalmente, para Pellegrini (2015), los paisajes rururbanos se observan en ámbitos rurales cercanos a la ciudad donde las actividades agropecuarias van perdiendo peso y productividad y son reemplazadas por modos de vida urbanos en un medio campestre. Esto nos permite reflexionar sobre la presión que ejerce lo urbano desde la competitividad, la productividad, el alto rendimiento, que conlleva en muchos de sus individuos y grupos sociales a un estrés que propicia la búsqueda de nuevos ambientes que generen menos caos. De esta forma los paisajes rururbanos se van constituyendo en la posibilidad de construir territorios que permiten distanciarse temporalmente de la vida urbana. Sin embargo estos paisajes son llamativos siempre y cuando se mantengan híbridos, ya que sus "seguidores urbanos" no se sienten conformes con el extremo de la vida rural o urbana.

\section{Rururbanización y gentrificación}

Para esta temática, uno de los principales referentes es Nates (2008), quien hace referencia a gentrificación en lugares rururbanos desde procesos de elitización de territorios que han sido habitados por poblaciones con poder adquisitivo bajo o medio y que han sido adquiridos por sectores medios y altos que presentan distintas características sociales y culturales. Este proceso puede conllevar en algunos casos a un vaciado de la población originaria. Sin embargo, la gentrificación no necesariamente implica una sustitución de un tipo de población por otra, si bien existe una lucha o una disputa por hacer prevalecer una determinada forma de concebir y practicar un territorio, esto no implica necesariamente que la población originaria desaparezca, ya que en un contexto de relaciones de poder, se llevan a cabo articulaciones políticas, económicas y sociales, que pueden ser de corte funcional, utilitarista o solidario para el alcance de diversos propósitos territoriales.

Este antecedente en contextos rururbanos tiene como referentes a autores de la gentrificación urbana que se remontan a Glass (1964) y a Smith (1996). El primero plantea este concepto para describir la invasión de ciertos barrios londinenses por personas de clase media y alta, y el consecuente desplazamiento de los habitantes originarios, acuñando el término gentrificación. Posteriormente Smith (1996) sostiene que esta se conecta a una reinversión (de capitales) en el centro a través de los poderes públicos y actores inmobiliarios privados, produciendo una nueva oferta de alojamientos de lujo en los antiguos barrios populares que lleva a un "reciclaje del barrio" o 'renovación'. Aunque este concepto surgió para explicar dinámicas territoriales en contextos urbanos, su aplicación se 
extendió a contextos rurales y rururbanos (Nates, 2008). Por otro lado autores como Lorenzen (2014) hacen referencia a la gentrificación rural como factor de persistencia de la población originaria y de las actividades agrícolas en Morelos, México, frente a lo cual se defiende un concepto de gentrificación más flexible y aplicable a otros ámbitos geográficos (espacios periurbanos y rurales) y a situaciones de nuevas construcciones inmobiliarias donde el fenómeno del desplazamiento no es generalizado.

\section{Rururbanización y campesinado}

En la discusión sobre rururbanización nos preguntamos, ¿dónde quedan las poblaciones campesinas y otros grupos sociales que son originarios de medios rurales? A partir del trabajo de campo realizado, entre 2015 y 2016, por Sánchez (2017), se ha podido constatar que aún hay campesinos en veredas en las que se niega su existencia por las administraciones municipales. Estas han sido planificadas como suelo de expansión urbano cuando se refiere a vivienda de estrato 2 y 3 ; y suburbano, al hacer referencia a vivienda estrato 5 y 6; o para complejos turísticos de acuerdo con lo establecido en los planes de ordenamiento territorial de los municipios de Villamaría, Manizales, Pereira, Circasia y Armenia, Colombia. Esta invisibilización del campesinado en contextos de rururbanización no solo se produce a través de gobiernos locales, regionales y nacionales, sino que se ha legitimado por los discursos académicos ergo Roseman, Prado y Pereiro (2013). Estos autores discuten que no se habla hoy de campesinos sino de poscampesinos dado que, aunque el campesino continúa existiendo, este ha cambiado mayoritariamente hacia un perfil empresarial y en muchas estructuras sociales ha pasado a ser residual porque son más abundantes otros agentes sociales tales como los neorurales, retornados, trabajadores rururbanos pendulares, exigiendo un cambio de lente. En esta vía, los autores que han abordado el estudio de la rururbanización hacen referencia a la poca o nula presencia de campesinos. Algunas investigaciones sobre rururbanización que siguen abordando al campesinado como categoría de análisis, establecen que el mundo rural ha pasado a un segundo plano y son las áreas rurales próximas a las ciudades las que sufren de manera más directa el mayor impacto. De acuerdo con González (2009) estas proveen el suelo sobre el cual crecen las ciudades, son receptoras de buena parte de los detritos que produce la ciudad, se deterioran al estar sometidas a procesos intensivos de extracción de materiales, se las convierten en depósito de materiales excedentes —en ocasiones tóxicos-, sus mejores suelos agrícolas son declarados zona de expansión urbana, gradualmente se convierten en zonas de recreo para fines de semana y son usados para 
actividades económicas conflictivas que expulsa la ciudad; y en relación con la población campesina que habita esta ruralidad próxima - especialmente la joven - se puede afirmar que las actividades agrícolas y pecuarias, conocimientos y vocaciones comienzan a desaparecer o se transforman de acuerdo con las nuevas realidades que ponen en entredicho la supervivencia de las formas de vida tradicionales. En esta investigación, el análisis de la transformación de lo rural pasa por cuestionar las dinámicas implícitas en el mejoramiento de las condiciones de vida urbanas. Se dilucidan las conexiones de interdependencia que presentan lo rural y lo urbano en un juego de relaciones de poder que afecta a todos los territorios. No solo se estudian las nuevas configuraciones sociales y productivas en lo rural, sino que también se ocupa de aquellos que han quedado rezagados dentro de los procesos de desarrollo.

Por otro lado Higuita (2013) plantea un estudio de caso en el que jóvenes del territorio rural del corregimiento de San Cristóbal, Medellín, Colombia, establecen que el proceso de expansión urbana genera un choque rural-urbano que impacta fuertemente la identidad territorial y que afecta a la comunidad, sus tradiciones, su cultura y su folclor, los cuales tienden a transformarse y a perderse. A través de este estudio se puede identificar lo que perciben los jóvenes como actores vulnerables frente a las dinámicas de expansión urbana por lo atractivo que resulta lo moderno, además que en muchas ocasiones los campesinos mayores han inculcado a sus hijos estudiar y buscar un buen trabajo en "la ciudad" porque el campo no es suficiente para vivir. Se podría tomar como referente este estudio para auscultar por algunas de las representaciones que se refieren a rechazar la vida en la vereda, lo que es preocupante porque se constituye el predominio de lo urbano sobre lo rural que no solo ha sido legitimado por los sectores económicos secundario y terciario sino que es legitimado políticamente a través del gobierno nacional, departamental y municipal generando desarraigo en la población campesina.

\section{Rururbanización y estudios territoriales: elementos de discusión}

Después de plantear cómo se ha abordado la rururbanización desde diversos autores y algunas categorías de análisis, a continuación se exponen algunos elementos de discusión y reflexión desde los estudios territoriales para el estudio del fenómeno. En esta medida no se podría atribuir las rururbanidades contemporáneas a un solo factor ya sean el mercado inmobiliario, las ideologías (Wallerstein, 2007), las políticas y 
la globalización, ya que es un fenómeno multidimensional y complejo que ha penetrado profundamente en las estructuras sociales y debe estudiarse desde sus múltiples relaciones. Este ha sido un tema algunas veces banalizado y asumido como un "lugar común, dado o determinado" referido principalmente a la parte física del territorio a través de la densidad de viviendas y planificado en función de esto, pero es tan profundo que ha conducido a la conformación de nuevos territorios. El territorio como espacio demarcado, delimitado, acotado, apropiado, significado para quienes lo habitan y que conlleva al establecimiento de fronteras que pueden ser visibles o invisibles producto de la pertenencia, las emociones, afectividades, representaciones (Hall, 1997), simbologías, prácticas, usos, historicidades, lenguajes (Turco, 2009), discursividades, luchas, confrontaciones, cooperaciones (Sennett, 2012) y solidaridades que se articulan desde el nivel micro y meso al macro, puesto que en las dinámicas y poderes locales para su construcción y defensa han influido el Estado, las capacidades institucionales y los poderes globales.

Este es un fenómeno con múltiples matices y aristas debido a que no solo relaciona clases medias y altas, sino que involucra diferentes grupos sociales con historias, trayectorias y representaciones que se instalan en el entorno rural modificándolo y transformándolo; sin embargo algunos autores también se refieren a rururbanidades en el espacio urbano, en el cual podrían incorporarse elementos de la vida rural.

Algunas de las explicaciones sobre la transformación de lo rural se tejen a través de la transición al modelo neoliberal que implicó la diversificación de actividades en el campo desde los noventa del siglo XX, incluyendo la localización de empresas alrededor de vías de comunicación estratégicas que conectan diversas municipalidades. Esto permitió el reordenamiento del espacio en función economicista y favoreció el asentamiento de pobladores, en algunos casos migrantes rurales, para hacer parte de las modalidades de integración atrofiada que conlleva el modelo de acumulación del capital (Arias, 2002). De esta forma, algunos de los grupos sociales y comunidades rurales dejaron de ser agricultores para "hacer parte" de dinámicas espaciales amplias, complejas y multidireccionadas con especializaciones definidas y dirigidas espacialmente hacia las manufacturas, las residencias, el turismo y las artesanías. Esto fue generando un ensamblaje de rururbanidades como producto y proceso funcional del mercado y del capitalismo mundial que se va extendiendo en la configuración del espacio heterogéneo (Santos, 1996) y en la transformación de los territorios. De acuerdo con las investigaciones de Arias (2002) los pueblos aledaños a Guadalajara, México, se convirtieron en comunidades dormitorio para alojar a los trabajadores de la ciudad; ya que la expansión urbana no ha sido producto únicamente de dinámicas 
demográficas espontáneas tal como lo establecen ciertos autores en defensa de políticas que procuran poner freno a la dinámica expansiva (Banzo, 2005).

Esta extensión y prolongación de la rururbanización debido a nuevas dinámicas que integran los usos y actividades que antes correspondían a "lo rural" o a "lo urbano" se relacionan con lo que pareciera ser una especie de tesitura espacial rururbana. Esta está relacionada con lo afirmado por Arias (2002) frente a la ciudad difusa, metápolis y a diferentes anillos que componen la difusión urbana en Francia como son: suburbios, periurbano, rururbano y rural. En esto que planteamos, quizá, como tesitura espacial rururbana, se otorgó mayor capacidad de movilidad y de operación a algunos individuos a costa de disminuir la libertad de los demás de vivir y practicar el territorio conforme a sus costumbres, controlando libertades. Por ello nos preguntamos: ¿qué significa la libertad en este contexto global desde una visión crítica de las rururbanidades?; ¿libertad para movilizarse, libertad para vivir dónde deseemos?

De acuerdo con Nates y Raymond (2007) las migraciones de los países delNorte de Europa hacialas zonas rurales delos países del Sury la migración interna hacia el sudoeste rural en Estados unidos, y las consecuencias que ello acarrea tales como la compra de considerables extensiones de tierra y de bienes de importancia patrimonial, es lo que ocasiona un alza desmesurada en los precios y deja a los nativos sin posibilidad de acceso. En este orden de ideas, Massey (1994) establece que cada vez que alguien utiliza el automóvil y aumenta su movilidad personal se reduce tanto la justificación social como la viabilidad financiera del sistema de transporte público y por lo tanto se reduce potencialmente la movilidad de aquellos que dependen de este sistema. Según Braidotti (2009) el tan acelerado fenómeno de la globalización y sus tecnologías realizan el truco del mago: combinan la celebración eufórica de las nuevas tecnologías, la nueva economía, los nuevos estilos de vida, las nuevas generaciones de dispositivos tanto humanos como tecnológicos, las nuevas guerras y las nuevas armas con el más absoluto rechazo social del cambio y la transformación.

Esto nos permite pensar que lo 'nuevo' implica que existen objetos, procesos, estilos de vida que son considerados 'viejos', 'obsoletos' y que necesitan renovarse o cambiarse por "algo mejor" desde los nuevos dispositivos tecnológicos, de seguridad, institucionales, habitacionales y de esquemas de representación que ofrece el Estado y los "nuevos mercados". De hecho, existen desarrollos tecnológicos que han magnificado las muchas desigualdades ya existentes en la sociedad contemporánea como aquellas entre ricos y pobres, entre hombres y mujeres y entre diferentes grupos raciales y étnicos (Soja, 2015). Estas libertades pueden desembocar en procesos de gentrificación o elitización de territorios (Smith, 1996; Nates, 
2008) a través de la construcción de amenidades por la localización de condominios y viviendas de lujo en entornos rurales que producen un aumento en "el precio" del suelo y por lo tanto mayores impuestos difíciles de asumir por los campesinos (Sánchez, 2017).

Según Elizalde y Thayer (2013), el sistema económico neoliberal ha sido causa del empobrecimiento de los agricultores pequeños y en general de la gente del campo con consecuencias ambientales destructivas a partir de la explotación en función del beneficio privado. Por ello acudimos a lo que parece ser un ordenamiento espacial diferenciado y sectorizado del campo frente a las rururbanidades contemporáneas. Esto relacionado con lo planteado por Arias (2002), Banzo (2005), Cimadevilla (2005), Dumont (2010), Urzúa (2013), Ringuelet (2008), Ribeiro (2011), Mejías (2013), Solana (2008) sobre la especialización de algunos sectores hacia actividades particulares ya sean la "agricultura campesina diversificada" — principalmente para el autoconsumo y comercialización del excedente- o la agricultura de mayor apertura hacia los mercados, el turismo "de campo y de naturaleza", las amenidades y vivienda de lujo, la localización de industrias y establecimientos comerciales, la vivienda para población urbana de bajos ingresos en "las periferias" entre otras actividades y usos del suelo.

En el plano de la literatura temática sobre rururbanidades encontramos diversos tipos de denominar a los pobladores: suburbanos, periurbanos, rururbanos, neocampesinos, neorurales, urbanitas y ciudadanos. Es así como las rururbanidades contemporáneas parecieran constituir un proceso de coexistencia entre antigüedad, modernidad y posmodernidad. La transformación de lo rural ha sido gradual y no excluye completamente lo antiguo (procesos precapitalistas) que permanece con las nuevas construcciones sociales y culturales, modernas y posmodernas. En la mayoría de los casos han cambiado las prácticas en los sistemas productivos para responder a una lógica de productividad y competitividad del agro, pero no en todos los casos, ya que en algunos sectores de veredas colombianas prevalecen los policultivos y prácticas agroecológicas. No es difícil encontrar entonces que mientras los nuevos pobladores urbanos incursionen en un "retorno al campo" (Nates y Raymond, 2007) enmarcado en la posmodernidad y en el posfordismo (Dematteis y Governa, 2005) los campesinos que incursionan en modos de vida urbanos estén apenas entrando en la Modernidad, aunque ya estaban inmersos en el campo y la naturaleza contrariamente con los anteriores. En esta medida el "derecho al campo" parece ser en la contemporaneidad, una cuestión de posmodernidad fundada en un ensamblaje que no ha dejado completamente de lado las bases sociales que la fundamentan desde la Antigüedad; aunque no las reconoce en los procesos de planificación y 
ordenamiento territorial, ni en los discursos académicos de hoy, frente a lo que implican las rururbanidades. Esto está transversalizado por la lógica del mercado que selecciona lo obsoleto y lo transable de acuerdo con las necesidades e intereses del capital.

En estas características de las rururbanidades, se evidencia una mayor necesidad de converger hacia las áreas naturales (Urzúa, 2013), establecer una mayor relación empresarial con los territorios (Courlet, 2002), generar procesos de urbanidad rural a partir de una mayor participación de los movimientos y organizaciones rurales frente a las dinámicas municipales (Deffontaines, 2003; Gumuchian et al., 2003). En este panorama, encontramos dos maneras de abordar la naturaleza. La primera por medio de las relaciones urbano-rurales que implican un proceso entre lo humano y lo no humano a nivel espacial y territorial (Sánchez, 2017) desde procesos biológicos, ecológicos y ecosistémicos en permanente relación entre espacios urbanos y rurales. Estas relaciones ecosistémicas permiten el flujo de materia y energía entre las diferentes especies. Es allí donde el concepto de interfase nos permite hacer alusión al punto de encuentro y superposición de sistemas distintos a través del cual pueden generarse múltiples canales de interrelación capaces de contener intensos flujos de materia, energía e información. Los corredores biológicos que permiten la conexión entre los diferentes ecosistemas urbano-rurales coexisten con diferentes comunidades barriales y veredales con diversidad de sistemas productivos que promueven el flujo de especies y nutrientes; cumplen funciones ecológicas de conexión entre reservas naturales; promueven espacios para la sustentabilidad y alternativa frente a los impactos ambientales del modelo de desarrollo. Se constituyen como cinturones que tienen funciones de restauración ambiental, depuración de gases contaminantes, actuar de pantalla frente al ruido, generación de microclimas, embellecer el paisaje, preservar los cauces de las corrientes de agua, conectar el sistema de espacios públicos y constituir un sistema para la depuración del aire a través de las plantas. De acuerdo con Braidotti (2009) una ética sustentable a favor de un sujeto no unitario propone un sentido ampliado de interconexión entre uno mismo y los otros que, al quitar el obstáculo del individualismo autocentrado, incluye a los otros no humanos o de la 'tierra'. Esto implica una nueva manera de combinar los intereses propios en un sentido más amplio de comunidad que abarca las interconexiones territoriales de cada uno. No obstante, y como lo expresa Harvey (1996), esta relación entre los procesos socioecológicos debe ser asumida desde una postura crítica debido a que en el conservacionismo hay múltiples intereses mercantiles. Por ello hay que analizar cuidadosamente cómo, quiénes y en qué localización del espacio se promueve la construcción de acercamientos y relaciones con la naturaleza. 
Esto nos conduce a la segunda forma de abordar la naturaleza en la rururbanización y que se denomina mimetismo eco-mercantil; el cual se establece en función de organizaciones empresariales y sociales a favor de la conservación de áreas naturales, pero con un trasfondo mercantilista de la naturaleza. En esta incluimos algunos pobladores urbanos que habitan el campo y buscan atraer extranjeros para el turismo de naturaleza, así como la localización de empresas inmobiliarias que se autorreconocen como "ambientalmente responsables" cuya trayectoria e instalación en espacios rururbanos, aunado a políticas de Estado, han promovido e intensificado la generación de procesos de gentrificación. En esta medida, la imagen de "lo verde" debe ser considerada cuidadosamente a través de intereses políticos y económicos ocultos.

Por último, otro elemento de discusión en este artículo para el abordaje de las rururbanidades contemporáneas desde los estudios territoriales corresponde a la construcción de nuevas identidades que no se ubican ni en lo urbano ni en lo rural propiamente. De acuerdo con Elías (1990), la relación entre la identidad como 'yo' y la identidad como 'nosotros' que posee cada persona singular no se establece de una vez y para siempre sino que está sometida a transformaciones muy específicas. La migración hacia el campo traduce notablemente en las sociedades occidentales nuevas búsquedas y exigencias en materia de calidad de vida (Nates y Raymond, 2007). Es difícil establecer una sola forma de rururbanidad, al igual que no podemos establecer una única cultura urbana (Nates, 2008), al tener en cuenta los modos de vida tan diversificados en el seno de la misma aglomeración. Sin embargo, aunque parece haber desaparecido las diferencias de identidad entre nativos y migrantes y también se asume que la construcción de identidades es un proceso básicamente compartido en un espacio, Arias (2002) afirma que la reconstrucción cuidadosa puede hacer emerger algo de lo que había en esos espacios; especialmente lo que pasó en el momento en que se suscitó la confluencia entre pobladores con historias, trayectorias políticas, imaginarios culturales y proyectos económicos distintos para ayudar a constatar las desapariciones, persistencias, readaptaciones, transformaciones y luchas. La rururbanización ha significadonosolocambios en las territorialidades campesinas sino también en las territorialidades de los pobladores urbanos que coproducen el rururbano a través de sus representaciones, valores, discursividades, prácticas y territorializaciones desde sus delimitaciones y acotaciones. De acuerdo con los estudios realizados por Sánchez (2017) en la vereda Canceles de Pereira, Risaralda, Colombia, los campesinos han empezado a demarcar y cerrar los predios que antes mantenían abiertos para evitar la posible entrada de 'ladrones' debido a la densificación urbana de las comunas que circundan la vereda 
y a los hurtos que se han presentado. Estos cerramientos se asemejan a la delimitación que se tiene en casas campestres y en condominios aledaños, lo que García (1976) denomina territorios reservados, cuya exclusividad posibilita que sean frecuentados solo por determinadas personas. Esto hace pensar que el campesino no es el mismo que se promueve en los estereotipos del sujeto de hace cincuenta, treinta o quince años. Nos referimos a que este sujeto también se ha transformado, quizá, algunos más que otros, hacia costumbres urbanas. ¿Querrá esto decir que deja de ser campesino?, ¿significará esto que es poscampesino o neocampesino? Consideramos que sigue siendo campesino, ya que su relación con la tierra es permanente. Tan solo ocurren procesos de incorporación de elementos a través de procesos adaptativos frente a las nuevas dinámicas territoriales. La forma como estas incorporaciones se insertan en los modos de vida campesinos son distintas a las que pueden acontecer en el sujeto que ha sido predominantemente urbano. Por ello, si vamos a hablar de un sujeto rururbano, no podemos homogeneizar porque realmente su esencia y vínculos tradicionales no son los mismos a pesar de admitir claramente su transformación.

En relación a esto, y a los lugares, Massey (1994) nos dice que si hoy se admite que la gente tiene múltiples identidades lo mismo puede decirse a propósito de los lugares. ¿Querrá decir esto que efectivamente los lugares que conforman los territorios rurales pueden dejar de ser eminentemente rurales para pasar a ser rururbanos? Podría establecerse que se transforman en rururbanos debido a que su metamorfosis es clara desde la construcción de diversos grupos sociales con culturas, intereses y formas de habitar distintas. Allí la multiplicidad trasciende una cultura, una economía, una forma política y se expresa en coexistencias, luchas y diferenciaciones que generan cambios en el territorio.

\section{Conclusión. Trazos y desafíos para estudios sobre rururbanización}

Frente a un panorama de múltiples intereses para la transformación de los territorios rurales, los desafíos se constituyen en reconocer cuál es la posición de los diversos actores en las relaciones de poder no solo a nivel global sino desde un conocimiento situado que permita constatar los elementos del pasado que se han filtrado al presente y se constituyen como tendencia a futuro, así como aquellos que ponen en duda su permanencia, pero que finalmente logran persistir y consolidarse en el territorio. Esto incluye las dinámicas sociales que no son fácilmente identificables en los paisajes producto de su ocultamiento a través de objetos modernos, discursos 
'oficiales', empresariales y de grupos sociales que tienen privilegios en el Estado. En esta medida, las rururbanidades se constituyen "no como la única transformación de lo rural" sino como una "poderosa transformación" que se ha ido consolidando lentamente como un proceso difícilmente reversible en materia de calidad de vida para quienes es una elección, considerando las necesidades y dinámicas del modelo de desarrollo y el modo de producción. Finalmente, en los estudios sobre rururbanización, vale la pena seguir profundizando desde algunos de los siguientes interrogantes: ¿qué papel cumplen las emociones, las sensibilidades, los arraigos en la construcción de los nuevos territorios?; ¿cómo las nuevas empresas que se instalan en los espacios rururbanos reconfiguran los territorios?; ¿qué conflictos territoriales permiten visibilizar tensiones e intereses ocultos para el estudio de las rururbanidades?; ¿qué alianzas, cooperaciones y solidaridades se generan en los espacios y territorios rururbanos de la contemporaneidad?

\section{Referencias bibliográficas}

Alberto, J.A. (2003). Paisajes urbanos y periurbanos. Ambiente y cultura. El caso del área metropolitana del Gran Resistencia (A.M.G.R.), Chaco. Recuperado de http://www.artes.unne.edu.ar/documentos/Extension/Paisajes\%20Culturales/EJE\%20 3/1-ALBERTO.pdf.

Arias, P. (2002). Hacia el espacio rural-urbano. Una revisión de la relación campo-ciudad en la antropología social mexicana. Estudios Demográficos y Urbanos, 17 (2), 363-381.

Ávila, H. (2009). La periurbanización y espacios rurales en la periferia de las ciudades. Recuperado de http://www.pa.gob.mx/publica/rev_41/analisis/7\%20hector\%20avila.pdf.

Banzo, M. (2005). Del espacio al modo de vida: la cuestión periurbana en Europa Occidental: los casos de Francia y España. En H. Ávila (Ed.), Lo urbano rural: ¿nuevas expresiones territoriales? Morelos, México: CRIM-UNAM.

Bastos, R. (2014). Entre lo rural y lo urbano. Recuperado de http://www.acuartaparede.com/ barrio-paisaxe-os-verdes-anos/?lang=es.

Bauer, G. et Roux, J.M. (1976). La rurbanisation ou la ville éparpillée. Paris, France: Editions Se.

Bericat, E. (2006). El cambio social en España. Visiones y retos de futuro. Sevilla, España: Centro de Estudios Andaluces.

Braidotti, R. (2009). Transposiciones. Barcelona, España: Editorial Gedisa.

Bran, M. (2016). Paisajes rururbanos. Recuperado de http://martabran.com/portfolio/paisajerururbano/.

Brown, D.L. and Kulcsár, L. (2000). Rural families and Rural Development in Central and Eastern Europe. Torún, Poland: Eastern European Countryside.

Cardoso, M. y Fritschy, B. (2012). Revisión de la definición del espacio rururbano y sus criterios de delimitación. Contribuciones Científicas GÆA, 24, 27-39.

Cimadevilla, G. (2005). De la dicotomía urbano-rural a la emergencia rurbana. Momentos y movimientos. Revista Esboços, 12 (13), 51-71.

Clout, H.D. (1976). Geografía rural. Barcelona, España: Oikos-Tau.

Courlet, C. (2002). Les systemes productifs localisés: Un bilan de la littérature. Cahier D'economie et Sociologie Rurales, 58-59, 82-103. 
Cosgrove, D. (1998). Social formation and symbolic landscape. Wisconsin, USA: University of Wisconsin.

Crovetto, M. (2011). Movilidad espacial, ocupación y empleo en el valle inferior del río Chubut (Patagonia, Argentina). Trabajo y Sociedad, 17 (XV), 363-380.

Crovetto, M. (2015). Dinámicas cotidianas rural-urbanas comparadas en la Patagonia Argentina: el valle inferior del río Chubut, la meseta central chubutense y el valle medio del río Negro. En Congreso ALAS. San José, Costa Rica.

Deffontaines, J.-P. (2003). Territoires et acteurs du développement local. De nouveaux lieux de démocratie. Paris, France: L'Aube.

Dematteis, G. y Governa, F. (2005). Territorio y territorialidad en el desarrollo local. La contribución del modelo SLOT. Turín, Italia: Universidad de Turín.

Dumont, M. et Heller, E. (Ed.) (2010). Péripheries sous condition urbaine: vieux probleme, nouveaux chantiers. Rennes, France: Presses Universitaires de Rennes.

Elías, N. (1990). La sociedad de los individuos. Madrid, España: Península.

Elizalde, A. y Thayer, L.E. (2013). Ruralidad y campesinado: ¿categorías en extinción o realidades en proceso de transformación? Polis, 12 (34), 7-12.

Errázuriz, A. et al. (1998). Manual de geografía de Chile. Santiago de Chile, Chile: Editorial Andrés Bello.

García, J. (1976). Antropología del territorio. Madrid, España: Taller de ediciones Josefina Betancor.

García Ramón, M.D. et al. (1995). Geografía rural. Madrid, España: Síntesis.

Glass, R. (1964). London, aspects of change. London, England: Macgibbon \& Kee Ltd.

Gómez, S. (2001). ¿Nueva ruralidad? Un aporte al debate. Recuperado de http://www.eco.unicamp.br/nea/rurbano.

González, A. (2009). Salvemos el espacio rururbano colombiano. Recuperado de http://revistas.javeriana.edu.co/index.php/cvyu/article/viewFile/5499/4310.

Gumuchian, H. et al. (2003). Les acteurs, ces oubliés du territoire. Barcelona, España: Anthropos.

Hall, S. (1997). Representation: Cultural Representations and Signifying Practices. London, England: Sage Publications.

Harvey, D. (1996). Justice, Nature and the Geography of Difference. Oxford, England: Blackwell's.

Hierneaux, D. (2001). Las nuevas formas urbanas y reestructuración del mundo rural. En P. Torres (Comp.), Procesos metropolitanos y agricultura urbana. Ciudad México, México: Universidad Autónoma Metropolitana.

Higuita, K. (2013). Jóvenes del territorio rural en el contexto de la expansión urbana. Estudio de caso, corregimiento San Cristóbal, Medellín, Colombia. Bitácora Urbano Territorial, 22 (1), 109-118.

Lanson, D. e Iglesias, A. (2011). Luján (provincia de Buenos Aires, Argentina): imagen y destino turístico. Contribución al análisis desde una perspectiva del patrimonio territorial. Recuperado de https://e-archivo.uc3m.es/bitstream/handle/10016/16484/lujan_lanson_iglesias_ TERAP_2011.pdf.

Lasanta, T. y Errea, M. (2012). Homogeneización y fragmentación en el paisaje rururbano de Logroño. Revista de Ciencias ZUBÍA, 30, 7-28.

Lefebvre, H. (2013). La producción del espacio. (E. Martínez Gutiérrez, Trad.) Capitán Swing Libros, S.L.

Llambí, L. (2012). Procesos de transformación de los territorios rurales latinoamericanos: los retos de la interdisciplinariedad. EUTOPÍA. Relación Campo Ciudad. Revista de Desarrollo Económico Territorial, 3, 117-134.

Lorenzen, M. (2014). La gentrificación rural como factor de persistencia de la población originaria y de actividades agrícolas: indicios desde Morelos, México. Revista Internacional de Ciencias Sociales, 3 (1), 1-14. 
Massey, D. (1994). A global sense of place. En D. Massey (Ed.), Space, Place and Gender. Minneapolis, USA: University of Minnesota Press.

Macuacé, R. y Cortés, R. (2013). Sobre migración y rururbanidad: adaptación y transformación de la ciudad de Popayán a comienzos del siglo XXI. Territorios, 29, 117-142.

Macuacé, R. y Gómez, A. (2014). Migración hacia los espacios rururbanos en Popayán (Colombia) para la primera década del siglo XXI. Revista Económica del Caribe. Recuperado de http://rcientificas.uninorte.edu.co/index.php/economia/article/view/6347/6567.

Mejías, V. (2013). ¿Cómo medir el fenómeno urban sprawl a través de indicadores paisajísticos? Aplicación a la isla de Tenerife. Boletín de la Asociación de Geógrafos Españoles, 62, 49-73.

Moquay, P. (2001). L'invention de nouveaux territoires: Une urbanité rurale. En Deffontaines, J.-P. Territoires et acteurs du développement local. De nouveaux lieux de démocratie (pp. 133141). Paris, France: L'Aube.

Nates, B. (2008). Procesos de gentrificación en lugares rururbanos: presupuestos conceptuales para su estudio en Colombia. Revista de Antropología y Sociología: VIRAJES, 10, 253-269.

Nates, B. y Raymond, S. (2007). Buscando la naturaleza. Migración y dinámicas rurales contemporáneas. Barcelona, España: Editorial Anthropos.

Pahl, R. (1966). The rural-urban continuum. Sociología Ruralis, 6, 299-327.

Pellegrini, C. (2015). El fenómeno de la periurbanización. Recuperado de http://www.diarionorte. com/article/95938/el-fenomeno-de-la-periurbanizacion.

Pérez, E. (2001). Hacia una nueva visión de la ruralidad. En N. Giarraca (Comp.), ¿Una nueva ruralidad en América Latina? Buenos Aires, Argentina: CLACSO.

Pesci, R. (2007). Proyectar la sustentabilidad. Buenos Aires, Argentina: Foro Latinoamericano de Ciencias Ambientales.

Ribeiro da Gusmao, F. (2011). Areas de interface periurbana: desafíos conceituais e metodológicos. En R. Randolph e B. Southern (Org.), Expansão metropolitana e transformação das interfaces entre cidade, campo e região na América Latina. São Paulo, Brasil: Max Limonade Editor.

Ringuelet, R. (2008). La complejidad de un campo social periurbano centrado en la zonas rurales de La Plata. Mundo Agrario, 9 (17).

Raffestin, C. (2011). Por una geografía del poder. Michoacán, México: El Colegio de Michoacán.

Rivera, J. (2013). Espacios de transición urbano-rural. Recuperado de

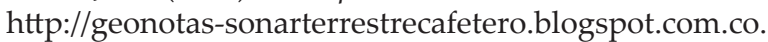

Roseman, S., Prado, S. y Pereiro, X. (2013). Antropología y nuevas ruralidades. Gazeta de Antropología, 29 (2), 1-17.

Sánchez, D. (2011). Plan de gestión ambiental para el corredor Otún Consotá de Pereira. Pereira, Colombia: Universidad Tecnológica de Pereira.

Sánchez, M.R. (2013). Propuesta de gestión ambiental en el contexto de la sustentabilidad para el espacio público natural urbano de la conurbación Pereira-Dosquebradas. Pereira, Colombia: Universidad Católica de Pereira.

Sánchez, M.R. (2013). Géneros de vida complejos y su expresión en el paisaje rururbano en Mixquic. Ciudad de México, México: Universidad Autónoma Metropolitana, Unidad Iztapalapa.

Sánchez, M.R. (2017). Latidos Veredales. Transformación de lo Rural y Configuración de Paisajes-Territorios Rururbanos en veredas de la Región Cafetera Colombiana (19702017). Investigación Doctoral. Doctorado en Estudios Territoriales. Instituto en Ciencias Sociales y Humanas. Universidad de Caldas. Texto inédito.

Santos, M. (1996). Metamorfosis del espacio habitado. Barcelona, España: Oikostau.

Sereno, C., Santamaría, M. y Santarelli, S. (2010). El rururbano: espacio de contrastes, significados y pertenencia, ciudad de Bahía Blanca, Argentina. Cuadernos de Geografía. Revista Colombiana de Geografía, 19, 41-57. 
Sereno, C. y Santarelli, S. (2012). El rururbano: un espacio de vulnerabilidad y riesgo. Estudio cualitativo en la ciudad de Bahía Blanca, provincia de Buenos Aires, Argentina. Buenos Aires, Argentina: Universidad Nacional del Sur.

Sennett, R. (2012). Juntos. Rituales, placeres y política de la cooperación. Madrid, España: Anagrama.

Smith, N. (1996). The New Urban Frontier: Gentrification And The Revanchist City. London, England: Routledge.

Soja, E. (2015). Justicia espacial. Barcelona, España: Editorial Tirant Lo Blanch.

Solana, M. (2008). El encanto de lo rural, los términos del debate sobre la migración hacia áreas rurales desde la geografía británica y las contribuciones españolas. Un estado de la cuestión. Recuperado de http://www.ub.edu/geocrit/b3w-776.htm.

Soria, L. y Goldwaser, B. (2012). Micro geografías: cambios en el uso del suelo en el territorio urbano de Buenos Aires (Argentina). Recuperado de http://hdl.handle.net/2099/14839.

Turco, A. (2009). Topogenèse: La généalogie du lieu et la constitution du territoire. En M. Vanier (Ed.), Territoires, territorialité, territorialisation. Controverses et perspectives (pp. 3744). Rennes, France: Presses Universitaires de Rennes.

Urzúa, K.E. (2013). ¿Gentrificación contemporánea en contexto urbano-rural chileno?: el caso de los condominios cerrados de las comunas del Alto Aconcagua (tesis de posgrado). Universidad de Chile, Santiago de Chile, Chile.

Wallerstein, I. (2007). Geopolitica y geocultura. Barcelona, España: Editorial Káiros.

Zucchetti, A. y Chirinos, C. (2001). Manejo alternativo de conflictos vinculados al uso del suelo en la cuenca del río Lurín, Lima, Perú. Recuperado de http://www.upeace.org/cyc/libro/pdf/ informes/fase_01/OACA_1.pdf. 